\title{
Synergistic anti-tumor effect of bullfrog sialic acid-binding lectin and pemetrexed in malignant mesothelioma
}

\author{
Toshiyuki Satoh ${ }^{1,2}$, Takeo Tatsuta², Shigeki Sugawara ${ }^{2}$, Akiyoshi Hara ${ }^{1}$ and \\ Masahiro Hosono ${ }^{2}$ \\ ${ }^{1}$ Department of Clinical Pharmacotherapeutics, Tohoku Medical and Pharmaceutical University, Aobaku, Sendai, Miyagi \\ 981-8558, Japan \\ ${ }^{2}$ Division of Cell Recognition Study, Institute of Molecular Biomembrane and Glycobiology, Tohoku Medical and Pharmaceutical \\ University, Aobaku, Sendai, Miyagi 981-8558, Japan
}

Correspondence to: Masahiro Hosono, email: mhosono@tohoku-mpu.ac.jp

Keywords: malignant mesothelioma, apoptosis, cell cycle, sialic acid-binding lectin, combination treatment

Received: December 28, $2016 \quad$ Accepted: April 06, $2017 \quad$ Published: April 18, 2017

Copyright: Satoh et al. This is an open-access article distributed under the terms of the Creative Commons Attribution License 3.0 (CC BY 3.0), which permits unrestricted use, distribution, and reproduction in any medium, provided the original author and source are credited.

\section{ABSTRACT \\ Malignant mesothelioma is an aggressive cancer with limited therapeutic options. Sialic acid-binding lectin isolated from Rana catesbeiana oocytes (CSBL) is a multifunctional protein with anti-cancer activity. The effects of pemetrexed, cisplatin, and CSBL were evaluated in mesothelioma and normal mesothelial cell lines. We evaluated cytotoxicity, apoptosis, caspase-3 cleavage and activation, cell proliferation, cell cycle arrest, and levels of cell cycle proteins in $\mathrm{H} 28$ cells treated with pemetrexed, cisplatin, and CSBL alone or in combination. Treatment with CSBL alone was cytotoxic to mesothelioma cells. The anti-cancer effect of CSBL was observed in a broader range of cell lines and exhibited greater cancer cell selectivity than pemetrexed or cisplatin. Combination treatment with pemetrexed + CSBL resulted in greater dose-dependent cytotoxicity than pemetrexed + cisplatin, the standard of care in mesothelioma. The synergistic effect of pemetrexed + cSBL was mediated by the cytostatic effect of pemetrexed and the cytotoxic effect of cSBL. It thus appears that CSBL has therapeutic potential for the treatment of mesothelioma.}

\section{INTRODUCTION}

Malignant mesothelioma is an aggressive cancer of mesothelial cell origin that results from exposure to asbestos $[1,2]$. Asbestos was extensively used in industry and construction during the 20th century. It was first associated with the incidence of mesothelioma in the 1960s [3-6]. Because mesothelioma develops 20-30 years after asbestos exposure, the number of mesothelioma patients is expected to increase [7-9]. There are few therapeutic options for mesothelioma. The folate antimetabolite pemetrexed is a chemotherapeutic that is typically used in combination with platinum-containing drugs such as cisplatin $[10,11]$. Compared to cisplatin monotherapy, combination treatment with pemetrexed + cisplatin improves response rate, progression-free survival, overall survival, and quality of life in mesothelioma patients [10]. However, most patients treated with pemetrexed and cisplatin experience tumor progression or relapse within a year $[12,13]$. Drug resistance is also commonly observed [14]. Therefore, alternative therapeutic agents for mesothelioma are needed.

Sialic acid-binding lectin isolated from Rana catesbeiana oocytes (cSBL) is a multifunctional protein with lectin-binding [15, 16], ribonuclease (RNase) [17], and anti-tumor activity [16]. cSBL is cytotoxic to cancer cells including leukemia [18-21], breast carcinoma [21-24], mesothelioma [25], and hepatoma cells [21, 26, 27]. It has little effect on normal cells such as fibroblasts, melanocytes, keratinocytes, and mesothelial cells [20, 21, 25, 26, 28]. cSBL-induced cell death involves at least three steps: (1) binding to the cell surface via carbohydrate chain containing sialic acid, (2) cell internalization, and (3) RNA cleavage and activation of apoptosis. The cytotoxic effects of cSBL are mediated by the induction of apoptosis in response to mitochondrial perturbation. RNase activity is essential for cSBL-induced cytotoxicity [24]. Treatment of tumor-bearing mice (transplanted with sarcoma 180 cells, Ehrlich, or Mep 2 ascites cells) with cSBL at a non-toxic dose prolonged 
survival [16]. In contrast to commonly used DNAtargeting agents, the cytotoxic effects of RNases are nongenotoxic [29]. Thus, cSBL has therapeutic potential as a novel RNA-targeting anti-cancer agent.

Combination chemotherapy is the standard of care for many cancers. It allows for the use of doses that maximize the therapeutic effects while preventing chemoresistance. cSBL has an anti-cancer effect in mesothelioma cell lines (e.g. NCI-H28 [H28], ACC-MESO-1 [MESO-1], and ACCMESO-4 [MESO-4]), and exhibited synergistic effects with tumor necrosis factor-related apoptosis-inducing ligand (TRAIL) in H28 cells [25] and interferon- $\gamma$ in hepatoma cell lines [27]. We investigated whether cSBL exhibited greater tumor selectivity than pemetrexed and cisplatin, and whether combination treatment with cSBL + pemetrexed was comparable or superior to combination treatment with pemetrexed + cisplatin.

\section{RESULTS}

\section{cSBL exhibits greater cancer cell selectivity than pemetrexed and cisplatin}

We evaluated the effects of cSBL, pemetrexed, and cisplatin on the viability of epithelioid mesothelioma cells (NCI-H2452 [H2452], MESO-1, and MESO-4), biphasic mesothelioma cells MSTO-211H (MSTO) and sarcomatoid mesothelioma cells (H28), and non-malignant mesothelial cells (MeT5A) using WST-8 assays. All three agents reduced mesothelioma cell viability. However, cSBL had the least effect on MeT5A cells (Figure 1). Even at the highest concentration $(20 \mu \mathrm{M})$, cSBL only inhibited MeT5A cell viability by $40 \%$ (Figure $1 \mathrm{C}$ ). In contrast, pemetrexed decreased Met5A cell viability by $50 \%$ at $0.01 \mu \mathrm{M}$ and cisplatin decreased viability by $70 \%$ at $10 \mu \mathrm{M}$. We calculated the half maximal inhibitory concentration $\left(\mathrm{IC}_{50}\right)$, defined as the concentration required to inhibit cell growth by $50 \%$, from dose-response curves. The relative sensitivity (RS) of each agent represents the ratio of the $\mathrm{IC}_{50}$ value in a cancer cell line to the $\mathrm{IC}_{50}$ value in MeT5A cells (Table 1). H2452, MESO-1, and MESO-4 cells were resistant to pemetrexed (RS: 0.37, 0.06, and 0.06, respectively), and $\mathrm{H} 28, \mathrm{H} 2452$, and MESO-1 cells were resistant to cisplatin (RS: 0.66, 0.24, and 0.26 , respectively). In contrast, cSBL was cytotoxic in these drug-resistant cell lines. The RS of cSBL was higher (9.48-247.02) than the RS values of pemetrexed and cisplatin in mesothelioma cells, indicating that the cytotoxic effect of cSBL was more selective to cancer cells.

\section{cSBL and pemetrexed exert a strong synergistic effect}

We investigated the pharmacological interaction between the three agents by evaluating the viability of H28 cells treated with pemetrexed + cisplatin, pemetrexed + cSBL, or cisplatin + cSBL. H28 cells are moderately sensitive to pemetrexed (Figure 1 and Table 1). We previously demonstrated that combination treatment with cSBL + TRAIL has a synergistic effect H28 cells [25]. The concentration of each drug in the combination regimen was based on the $\mathrm{IC}_{50}$ value of each agent as a single treatment. Pemetrexed + cisplatin and pemetrexed $+\mathrm{cSBL}$ reduced cell viability to a similar extent (Figure 2A). To evaluate the synergistic effect of each drug combination, we calculated combination index (CI) values. The CI curves shown in Figure 2B indicated that pemetrexed + cSBL had a stronger synergistic effect and broader fraction affected $(\mathrm{Fa})$ range than the other combinations. Cisplatin $+\mathrm{cSBL}$ exhibited the weakest cytotoxic and synergistic effects. We also calculated the concentration of each agent at $\mathrm{Fa}=0.5$ (i.e., the concentration predicted to reduce cell viability by $50 \%$ ) (Table 2 ). Lower concentrations of each agent were required to inhibit cell viability by $50 \%$ when they were combined rather than administered a single agents. The concentration of pemetrexed decreased by nearly $50 \%$ when used in combination with cSBL $(0.38 \mu \mathrm{M})$ compared to cisplatin $(0.65 \mu \mathrm{M})$.

\section{Pemetrexed and cSBL induce apoptosis in mesothelioma cells}

We previously demonstrated that cSBL induces apoptosis in $\mathrm{H} 28$ (sarcomatoid histological type) as well as MESO-1 and MESO-4 (epithelioid type) cells, and that the synergistic anti-tumor effect of cSBL + TRAIL in H28 cells was mediated by an increase in apoptosis [25]. To elucidate the mechanism underlying the synergistic effect of pemetrexed + cSBL in $\mathrm{H} 28$ cells, we evaluated markers of apoptosis. In the initial combination treatment experiments (Figure 2A), pemetrexed $(20 \mu \mathrm{M})$, cisplatin $(40 \mu \mathrm{M})$, and cSBL $(1 \mu \mathrm{M})$ reduced the viability of $\mathrm{H} 28$ cell lines to similar levels (approximately 30\%). Therefore, we used these concentrations in all subsequent experiments. After $72 \mathrm{~h}$ of treatment, the percentage of annexin V-positive cells was $27.3 \%, 38.7 \%$, and $44.3 \%$ in cells treated with pemetrexed, cisplatin, and cSBL, respectively, and 44.8\%, 47.3\%, and $46.0 \%$ in cells treated with pemetrexed + cisplatin, pemetrexed $+\mathrm{cSBL}$, and cisplatin $+\mathrm{cSBL}$, respectively (Figure 3). There were no statistically significant differences between the individual and combination treatments.

\section{The synergistic effect of pemetrexed + cSBL is not mediated by changes in caspase- 3 activity}

To investigate whether the synergistic anti-tumor effect of pemetrexed + cSBL was mediated by apoptosis, we analyzed activated caspase- 3 levels. Western blot analysis demonstrated that all of the treatments increased activated caspase-3 levels (Figure 4A). Caspase-Glo ${ }^{\mathrm{TM}}$ 3/7 assays indicated pemetrexed and cisplatin did not induce caspase- 3 activation. In contrast, a significant increase in activated caspase-3 was observed in cells treated 
with cSBL alone or with any of the three combination treatments (Figure 4B). There were no significant differences in caspase-3 activity between cells treated with cSBL alone or the combination treatments.

\section{Pemetrexed and cisplatin inhibit cell proliferation, but cSBL has a cytotoxic effect in H28 cells}

Because apoptosis was not upregulated with the addition of pemetrexed to cSBL, we investigated the mechanism by which pemetrexed and cSBL inhibited mesothelioma cell viability. Previous reports have indicated that the anti-tumor effect of both pemetrexed and cisplatin is mediated by the induction of apoptosis in response to cell cycle arrest [30-35]. Therefore, we analyzed the effect of pemetrexed and cisplatin on cell proliferation. The total number of cells decreased by $10.4 \%, 14.2 \%$, and $32.7 \%$ in cells treated with pemetrexed, cisplatin, and cSBL, respectively, for $72 \mathrm{~h}$ compared to control (PBS-treated) cells (Figure 5A). The ratio of annexin $\mathrm{V}$ - and propidium iodide (PI)-positive cells indicated that the number of dead cells barely increased in response to pemetrexed-

A

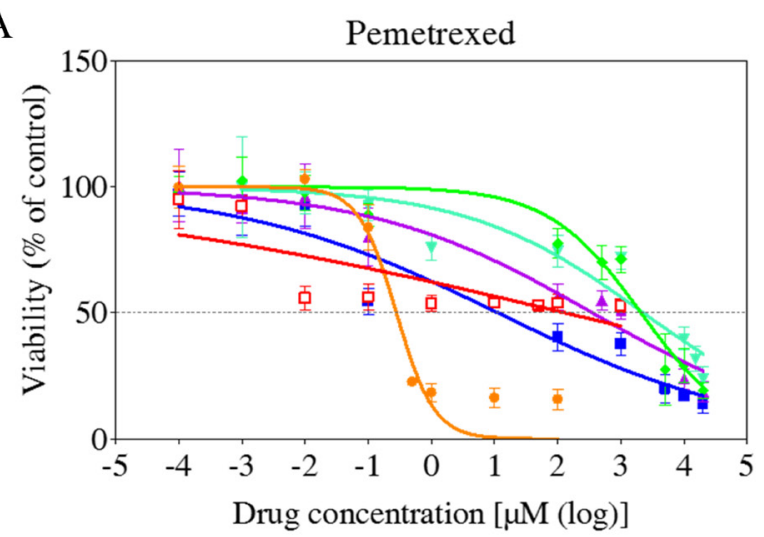

$\mathrm{C}$

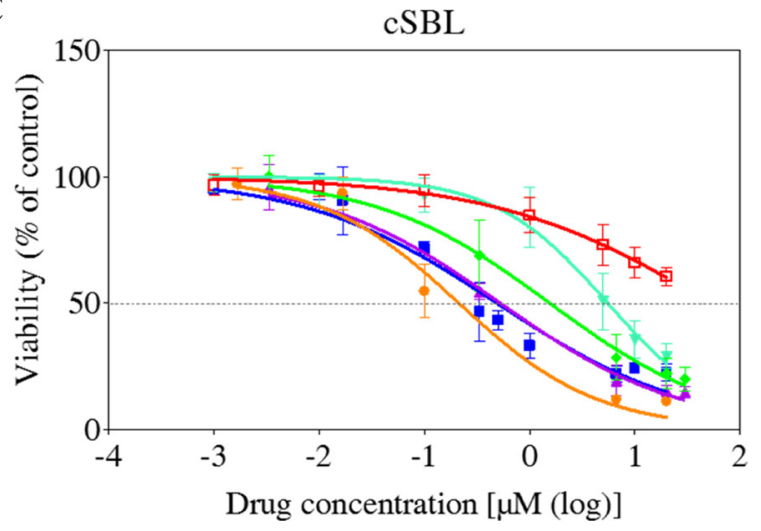

or cisplatin treatment, whereas the number of dead cells significantly increased with cSBL treatment (Figure 5B).

\section{The anti-tumor activity of pemetrexed + cSBL is mediated by cytostatic and cytotoxic effects}

Cell viability assays suggested that pemetrexed and cisplatin inhibited proliferation. Therefore, we analyzed cell cycle progression in H28 cells treated with these agents. Flow cytometry analysis revealed that pemetrexed and cisplatin induced cell cycle arrest in $\mathrm{S}$ phase and the S or G2 phase, respectively. In contrast, cSBL had a minimal effect on cell cycle progression. However, it promoted a significant increase in the number of cells in the sub-G1 phase, indicative of apoptosis. DNA histograms of cells treated with the combination treatments resembled the histograms of cells treated with the individual agents (pemetrexed + cisplatin: $\mathrm{S}$ phase arrest, pemetrexed + cSBL: $\mathrm{S}$ phase arrest and sub-G1 increment, and cisplatin + cSBL: S or G2 phase arrest and sub-G1 increment) (Figure 6A and 6B). To investigate the molecular mechanisms underlying these effects, we assessed the levels of proteins that regulate

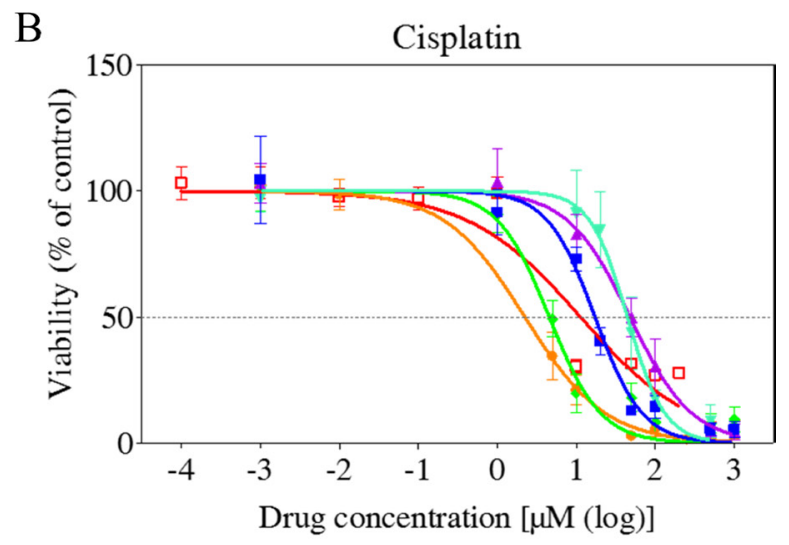

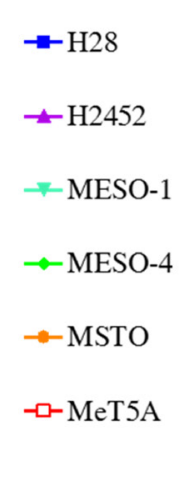

Figure 1: Dose-response curves in the mesothelioma cell lines (H28, H2452, MESO-1, MESO-4, and MSTO), and MeT5A mesothelial cells treated with pemetrexed (A), cisplatin $(\mathbf{B})$, or cSBL $(\mathbf{C})$. Cells were treated with pemetrexed $(0.1 \mathrm{nM}-20 \mathrm{mM})$, cisplatin (1 nM-1 mM), or cSBL $(1 \mathrm{nM}-30 \mu \mathrm{M})$ for $72 \mathrm{~h}$. The dots and bars represent the mean and SD, respectively. Dose-response curves are depicted as lines or dotted lines. Each data point represents the mean $\pm \mathrm{SD}$ of at least three independent WST- 8 assays. Each sample was plated in triplicate. 
Table 1: $\mathrm{IC}_{50}$ values $(\mu \mathrm{M})$ and $\mathrm{RS}$ of pemetrexed, cisplatin, and cSBL in mesothelioma cells

\begin{tabular}{|c|c|c|c|c|c|c|c|c|}
\hline Drugs & Drug targets & & MeT5A & $\mathrm{H} 28$ & H2452 & MESO-1 & MESO-4 & MSTO \\
\hline \multirow{3}{*}{ Pemetrexed } & TS & \multirow{2}{*}{$\mathrm{IC}_{50}$} & 129.50 & 11.27 & 353.00 & 2267.00 & 2077.00 & 0.28 \\
\hline & $\overline{\text { DHFR }}$ & & $(24.20-693.20)$ & $(5.67-22.39)$ & $(208.6-597.3)$ & $(1393-3691)$ & (1634-2639) & $(0.23-0.34)$ \\
\hline & $\overline{\text { GRAFT }}$ & RS & 1.00 & 11.49 & 0.37 & 0.06 & 0.06 & 465.99 \\
\hline \multirow{3}{*}{ Cisplatin } & \multirow{3}{*}{ DNA } & \multirow{2}{*}{$\mathrm{IC}_{50}$} & 11.27 & 17.18 & 47.62 & 44.14 & 4.54 & 2.23 \\
\hline & & & $(8.07-15.73)$ & $(15.14-19.50)$ & $(41.23-55.00)$ & (38.62-50.46) & $(3.87-5.33)$ & $(1.62-3.06)$ \\
\hline & & $\mathrm{RS}$ & 1.00 & 0.66 & 0.24 & 0.26 & 2.48 & 5.06 \\
\hline \multirow{3}{*}{$\mathrm{cSBL}$} & \multirow{3}{*}{ RNA } & \multirow{2}{*}{$\mathrm{IC}_{50}$} & 52.22 & 0.46 & 0.52 & 5.51 & 1.54 & 0.21 \\
\hline & & & (33.94-80.36) & $(0.35-0.68)$ & $(0.41-0.66)$ & $(4.67-6.50)$. & $(1.10-2.17)$ & $(0.15-0.29)$ \\
\hline & & $\mathrm{RS}$ & 1.00 & 113.89 & 100.00 & 9.48 & 33.91 & 247.02 \\
\hline
\end{tabular}

The $95 \%$ confidence intervals for each $\mathrm{IC}_{50}$ value are shown in parentheses. The RS value was calculated as the $\mathrm{IC}_{50}$ value of each agent in MeT5A cells divided by the $\mathrm{IC}_{50}$ value in each cancer cell line.

cell cycle progression (cyclin, p21 $1^{\text {Wafl/Cip1 }}$, and Akt) by western blotting. The levels of cyclin A and p21 Wafl/Cipl were unchanged in cells treated with pemetrexed alone, while the levels of phosphorylated Akt significantly increased. Cyclin A and B1 levels significantly decreased in cisplatin-treated cells, while $\mathrm{p} 21^{\text {Wafl/Cipl }}$ levels increased. In contrast, cyclin A, B1, D1, and E levels, and as well as $\mathrm{p} 21^{\text {Wafl/Cip1 } 1}$ and phosphorylated Akt levels, significantly decreased in cSBL-treated cells. The levels of cyclin A and $\mathrm{B} 1$ decreased, whereas $\mathrm{p} 21^{\text {Wafl/Cip1 }}$ levels increased in cells treated with pemetrexed + cisplatin. Pemetrexed + cSBL, and cisplatin + cSBL, significantly decreased cyclin B1, p2 $1^{\text {Wafl/Cip1 }}$, and phosphorylated Akt levels, similar to those observed in cells treated with cSBL alone, whereas pemetrexed $+\mathrm{cSBL}$ had the same effect on cyclin A levels as treatment with pemetrexed alone (Figure 6C).

A

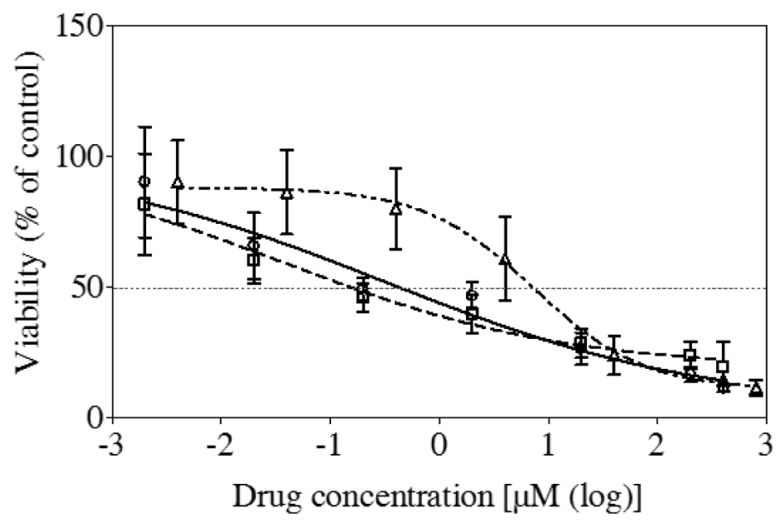

\section{DISCUSSION}

Mesothelioma is categorized as one of three histological subtypes: epithelioid, biphasic, or sarcomatoid $[1,36]$. Previous studies have demonstrated that the epithelioid subtype is associated with more favorable survival outcomes compared to non-epithelioid subtypes $[1,37,38]$. We found that cSBL had strong cytotoxic effects in a broader range of mesothelioma cell types including pemetrexed- or cisplatin-resistant cells. We previously demonstrated that cSBL selectively bound to 20 human and animal cancer cell lines but not to 10 normal cell lines [15]. A comprehensive analysis of cSBL cytotoxicity and cancer selectivity was performed previously $[39,40]$. We found that cSBL preferentially binds and internalizes into cancer cells compared to

B

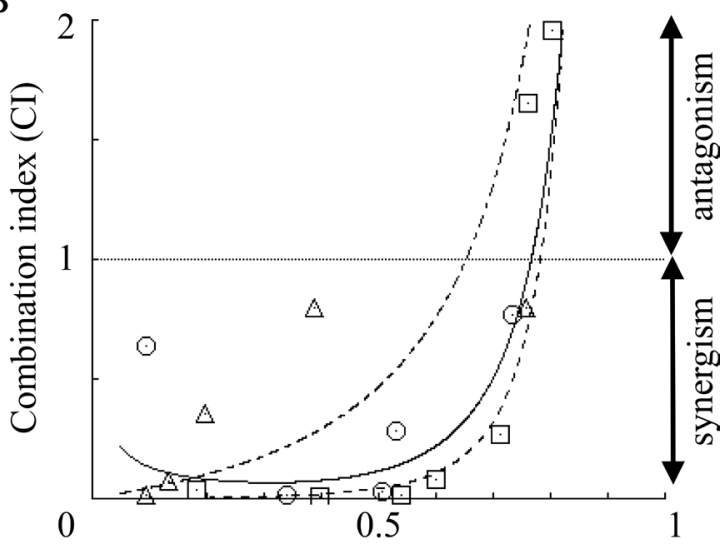

Fraction affected $(\mathrm{Fa})$

\footnotetext{
-Pemetrexed + Cisplatin

$-\square \cdot$ Pemetrexed $+\mathrm{cSBL}$

$-\Delta$ Cisplatin + cSBL
}

Figure 2: Pharmacological interactions between pemetrexed, cisplatin, and cSBL in $\mathbf{H} 28$ cells. (A) The drug concentration ratios were as follows: pemetrexed + cisplatin (1:2), pemetrexed + cSBL (20:1), cisplatin + cSBL (40:1). Cells were treated with pemetrexed $(2 \mathrm{nM}-400 \mu \mathrm{M})$, cisplatin $(4 \mathrm{nM}-800 \mu \mathrm{M})$, or cSBL $(0.1 \mathrm{nM}-20 \mu \mathrm{M})$ for $72 \mathrm{~h}$. The horizontal axis indicates the concentration of pemetrexed in the pemetrexed + cisplatin or pemetrexed $+\mathrm{cSBL}$ combination or the concentration of cisplatin in the cisplatin + cSBL combination. (B) CI-Fa curves for $\mathrm{H} 28$ cells treated with pemetrexed + cisplatin, pemetrexed + cSBL, or cisplatin + cSBL. CI values $<1$ indicate a synergistic effect, and CI values $>1$ indicate an antagonistic effect. Each data point represents the mean \pm SD of three independent WST- 8 assays. Each sample was plated in triplicate. 
Table 2: $\mathrm{CI}$ values and drug concentrations at $\mathrm{Fa}=0.5$ in $\mathrm{H} 28$ cells

\begin{tabular}{|c|c|c|c|c|c|}
\hline & \multirow{2}{*}{ Drug/Combo } & \multirow{2}{*}{ CI value } & \multicolumn{3}{|c|}{ Concentration at $\mathbf{F a}=0.5$} \\
\hline & & & Pemetrexed $(\mu \mathrm{M})$ & Cisplatin $(\mu \mathbf{M})$ & $\operatorname{cSBL}(\mu \mathrm{M})$ \\
\hline \multirow{3}{*}{ Single } & Pemetrexed & - & 20.44 & - & - \\
\hline & Cisplatin & - & - & 15.2 & - \\
\hline & $\mathrm{cSBL}$ & - & - & - & 0.69 \\
\hline \multirow{3}{*}{ Combination } & Pemetrexed + Cisplatin & 0.12 & 0.65 & 1.31 & - \\
\hline & Pemetrexed + cSBL & 0.05 & 0.38 & - & 0.02 \\
\hline & Cisplatin + cSBL & 0.47 & - & 4.6 & 0.12 \\
\hline
\end{tabular}

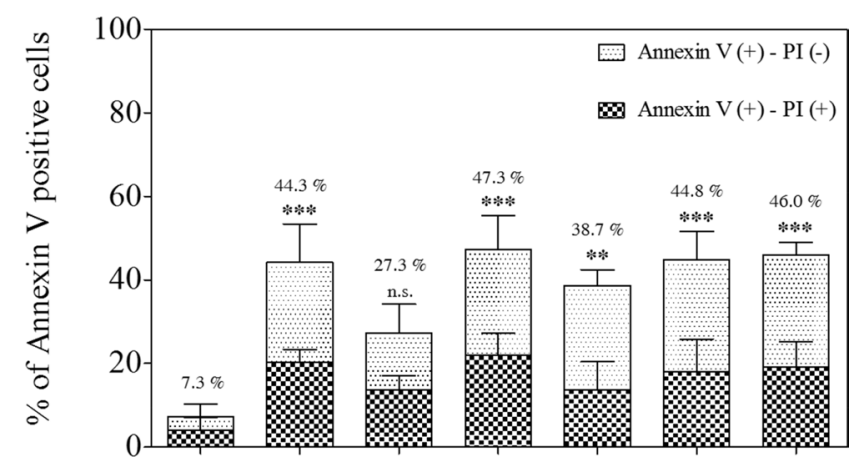

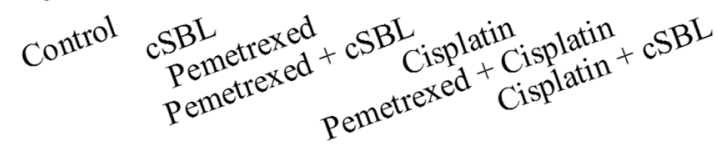

Figure 3: Pemetrexed, cisplatin, and cSBL, either alone or in combination, induced apoptosis in $\mathrm{H} 28$ cells. Cells were treated with pemetrexed $(20 \mu \mathrm{M})$, cisplatin $(40 \mu \mathrm{M})$, or cSBL $(1 \mu \mathrm{M})$ for $72 \mathrm{~h}$. The y-axis indicates the percentage of annexin V-positive cells. The percentage of PI-positive and negative cells is indicated by the different column patterns. The statistical significance of the percentage of annexin V-positive cells compared to the control is shown. ${ }^{*} p<0.01,{ }^{* * *} p<0.001$; n.s.: not significant.

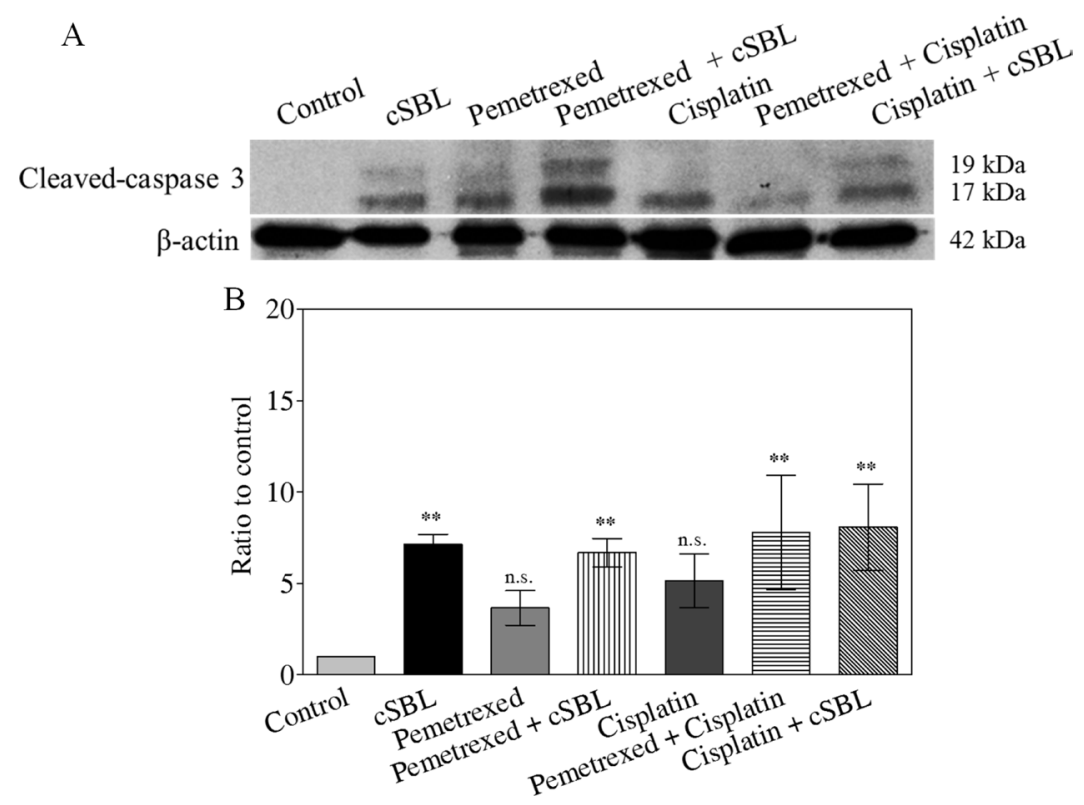

Figure 4: Caspase-3 activation is not enhanced by combination treatment. Cells were treated with pemetrexed $(20 \mu \mathrm{M})$, cisplatin $(40 \mu \mathrm{M})$, or cSBL $(1 \mu \mathrm{M})$ for $72 \mathrm{~h}$. (A) Cleaved (activated) caspase-3 was detected using western blot analysis. (B) Caspase-3 activity was analyzed using a Caspase-Glo ${ }^{\mathrm{TM}} 3 / 7$ assay. ${ }^{*} p<0.05$; n.s.: not significant. 
normal cells, and exerts cytotoxic effects through its RNase activity [16]. Internalization-defective P-388 mutant (RC-150) cells, which are cSBL-resistant, can bind cSBL but show no cytotoxicity [41]. Therefore, we hypothesize that the lack of specific internalization of cSBL could make normal cells non-sensitive.

Although the effects of cSBL in combination with other agents have been investigated in various cancer cell lines $[21,25,27]$, there have been no reports describing the effects of cSBL in combination with pemetrexed or cisplatin. We have demonstrated that the synergistic effect of pemetrexed $+\mathrm{cSBL}$ is comparable to that of pemetrexed + cisplatin (Figure 2A and 2B). Treatment with pemetrexed + cSBL could decrease the risk of dose-dependent adverse effects associated with pemetrexed and/or the development of pemetrexed resistance. The synergistic effect of pemetrexed $+\mathrm{cSBL}$ is not mediated by increased apoptosis (Figures 3, 4). Apoptosis is commonly observed in cancer cells treated with relatively high concentrations of anticancer agents, whereas a cytostatic effect (i.e. transient growth arrest) is typically observed with relatively low concentrations [42]. We found that the percentages of annexin V/PI double-positive cells (Figure 3 ) and dead cells in the Muse ${ }^{\mathrm{TM}}$ analysis (Figure 5) of pemetrexedor cisplatin-treated cells were comparable and relatively low (13-17\%). Cell cycle analysis (Figure 6) indicated that pemetrexed and cisplatin exert cytostatic effects, whereas cSBL exerts cytotoxic effects. These data suggest that pemetrexed- and cisplatin-treated cells proceed to an early apoptotic stage, but that cSBL is required for completion of apoptosis. The differential effects of each agent on cell cycle proteins suggest that the molecular mechanisms underlying cell cycle arrest are dependent on the cell type and the specific treatment. Pemetrexed reportedly induces S-phase arrest in A549 lung cancer cells by prolonging Akt activation, thereby sustaining
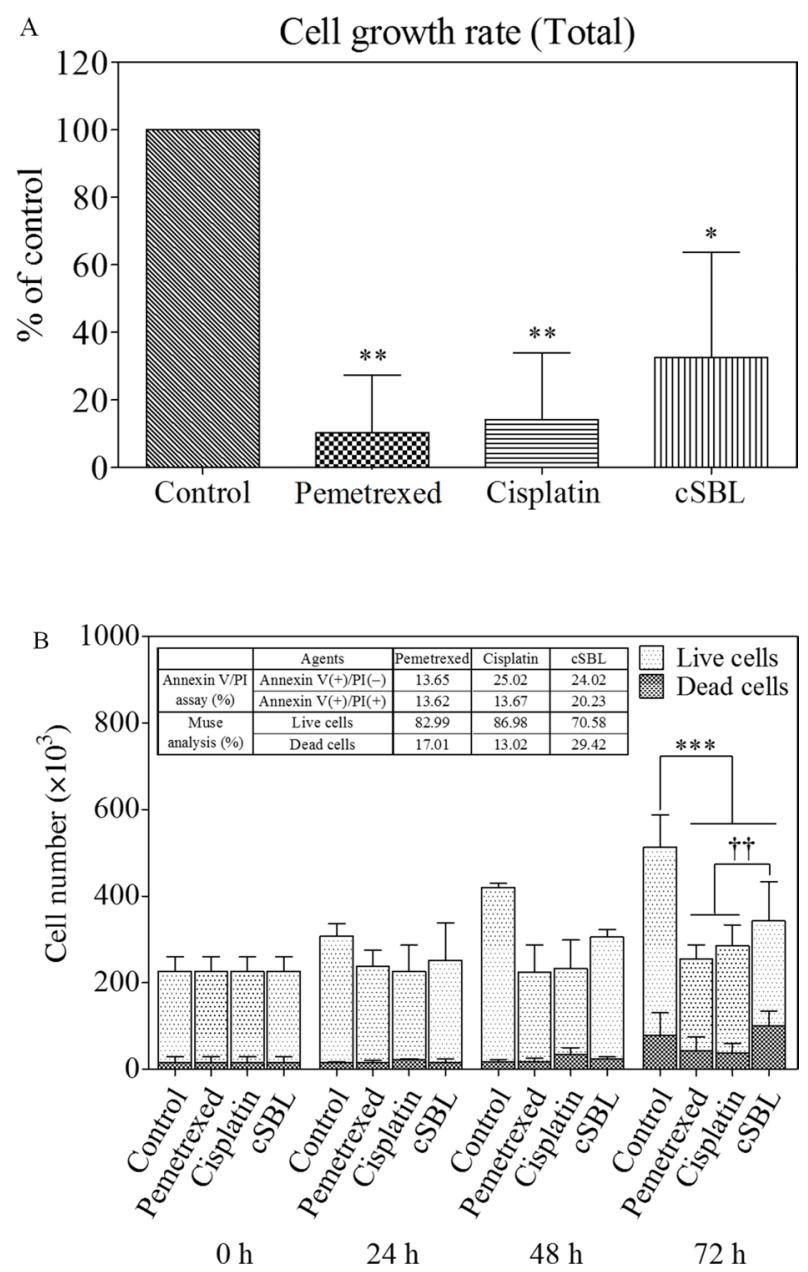

Figure 5: Pemetrexed and cisplatin inhibit proliferation, whereas cSBL has a cytotoxic effect in $\mathrm{H} 28$ cells. Cells were treated with pemetrexed $(20 \mu \mathrm{M})$, cisplatin $(40 \mu \mathrm{M})$, or cSBL $(1 \mu \mathrm{M})$ for $0-72 \mathrm{~h}$. The number of cells was estimated using a Muse ${ }^{\mathrm{TM}} \mathrm{Count} \&$ Viability Kit. (A) Cell growth rates were calculated as the ratio of the cell number at $72 \mathrm{~h}$ to the cell number at $0 \mathrm{~h}$ and presented as a fraction of the controls. (B) The number of live and dead cells every $24 \mathrm{~h}$ is shown. Statistically significant differences in the live cell number at $72 \mathrm{~h}$ were observed in the treatment groups compared to the control $(* * *)$. Statistically significant differences in the dead cell number at $72 \mathrm{~h}$ were observed in cSBL-treated cells compared to cisplatin- or pemetrexed-treated cells ${ }^{\dagger \dagger}$ ). ${ }^{*} p<0.05,{ }^{* *} p<0.01,{ }^{* * *} p<0.001,{ }^{\dagger} p<0.01$. 
activation of CDK2/cyclin A kinase [31]. In our study, pemetrexed treatment did not significantly alter the levels of cyclin A. However, pemetrexed induced an increase in phosphorylated Akt levels and arrested cells cycle in S-phase (Figure 6). The levels of the cyclins evaluated as well as p $21^{\text {Waf1/Cip1 }}$ levels significantly decreased in cSBL- treated cells. Since cSBL inhibits RNA translation through degradation, short-lived proteins such as cyclins are likely to be sensitive to cSBL treatment. Interestingly, in cells treated with pemetrexed $+\mathrm{cSBL}$, although the levels of cyclin B1, D1, and E, p21 Wafl/Cip1, and phosphorylated Akt significantly decreased to levels similar to those observed

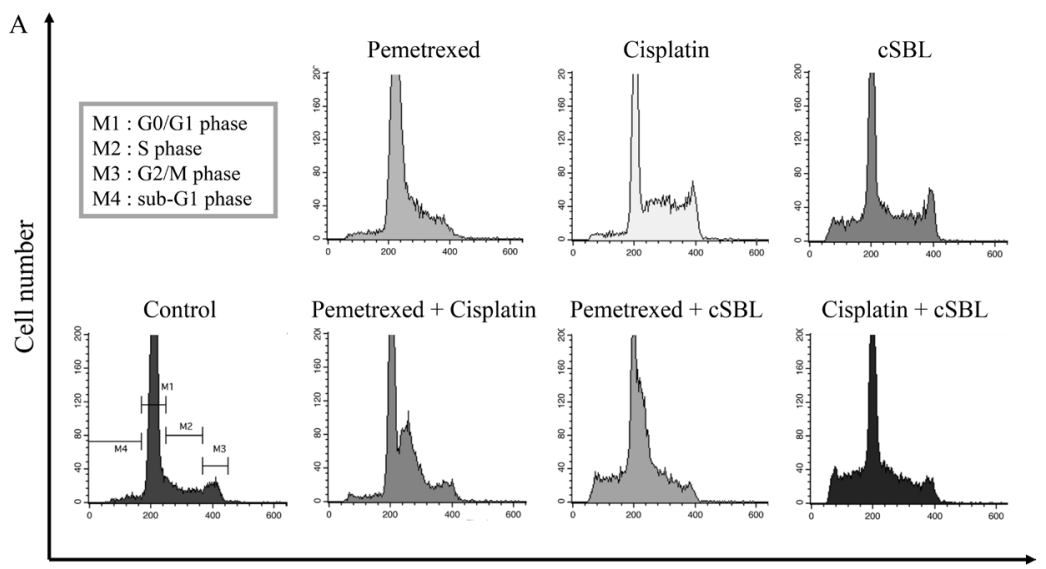

DNA content

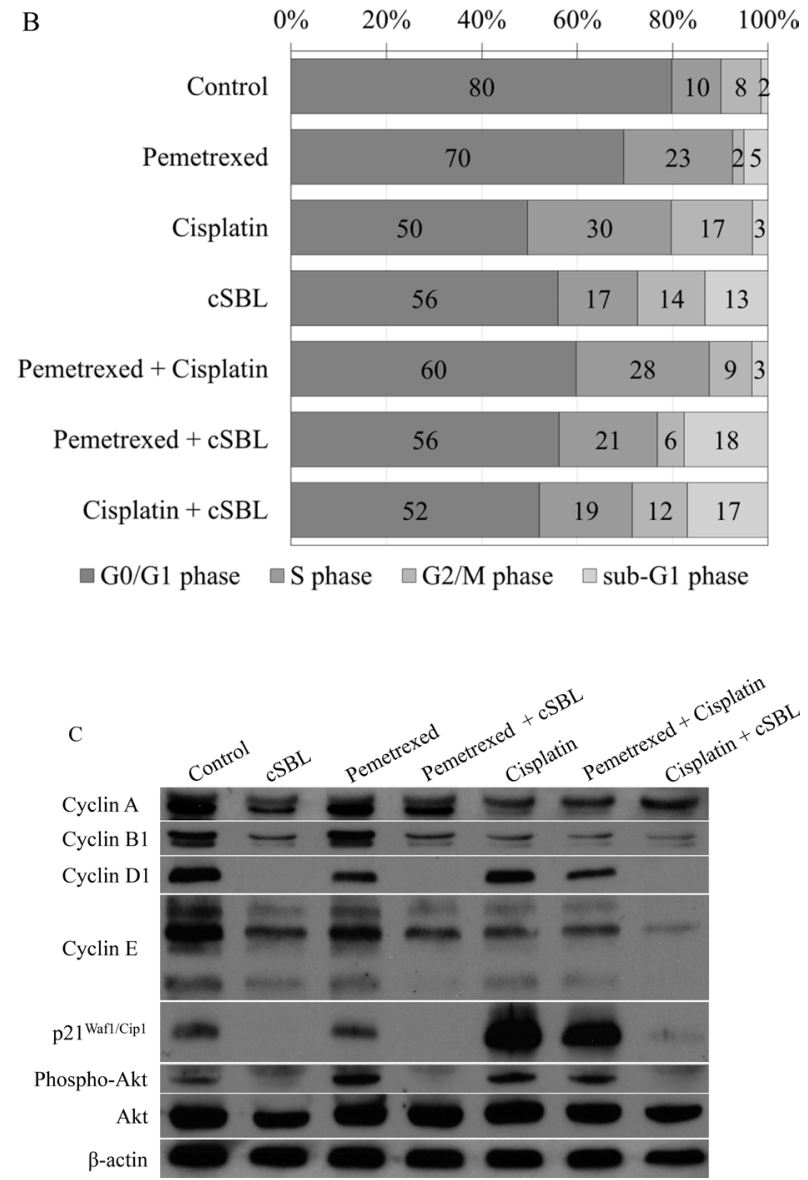

Figure 6: Pemetrexed, cisplatin, and cSBL, either alone or in combination, alter cell cycle dynamics in $\mathrm{H} 28$ cells. Cells were treated with pemetrexed $(20 \mu \mathrm{M})$, cisplatin $(40 \mu \mathrm{M})$, or cSBL $(1 \mu \mathrm{M})$ for $72 \mathrm{~h}$. (A, B) Flow cytometry analysis of cell cycle progression in $\mathrm{H} 28$ cell lines after $72 \mathrm{~h}$ of treatment. (C) Western blot analysis of cyclin (A, B1, D1, and E), p21 $1^{\text {Wafl/Cipl }}$, pan-Akt, and phospho-Akt levels. 
in cells treated with cSBL alone, cyclin A levels did not significantly change. Although cSBL may inhibit cyclin A translation, pemetrexed might stabilize cyclin A levels and enhance CDK2/cyclin A kinase activity, thereby inducing S-phase arrest and/or apoptosis when used in combination with cSBL [43-45]. The strong synergism of pemetrexed $+\mathrm{cSBL}$ is mediated by the cytostatic action of pemetrexed triggered by sustained CDK2/cyclin A activation, and the proapoptotic effect of cSBL.

The levels of $\mathrm{p} 21^{\mathrm{Wafl} / \mathrm{Cip} 1}$ were differentially affected by each treatment. The tumor suppressor $\mathrm{p} 21^{\text {Wafl/Cip } 1}$ arrests cell cycle progression by inhibiting the function of cyclin-CDK complexes or DNA polymerase [46-48]. Overexpression of $\mathrm{p} 21^{\mathrm{Wafl} / \mathrm{Cip} 1}$ induces cell cycle arrest in G1-, G2- [49], or S-phase [50, 51]. Pemetrexed and cisplatin induce cell cycle arrest by increasing $\mathrm{p} 21^{\text {Waf1/Cip } 1}$ levels $[30,52]$. As a single treatment, pemetrexed did not change $\mathrm{p} 21^{\text {Wafl/Cip1 }}$ levels. However, cisplatin and cSBL significantly increased and decreased p $21^{\text {Wafl/Cip1 }}$ levels, respectively. Of the combination treatments evaluated, only pemetrexed + cisplatin substantially increased $\mathrm{p} 21^{\text {Waf1/Cip } 1}$ levels. Therefore, $\mathrm{p} 21^{\text {Wafl/Cip1 }}$ may be important for cisplatininduced cell cycle arrest in $\mathrm{H} 28$ cells. Indeed, p2 $1^{\text {Waf1/Cip1 }}$ induced apoptosis in MSTO cells treated with a combination of cisplatin and piroxicam. Silencing p $21^{\text {Waf1/Cipl }}$ inhibited this effect [53]. Because cisplatin strongly increased p21 Waf1/ ${ }^{\text {Cip1 }}$ in $\mathrm{H} 28$ cells (Figure 6), we propose that the decrease of p21 Wafl/Cip1 levels in cSBL-treated cells might explain the lack of synergy between cisplatin and cSBL. Lazzarini et al. reported that shRNA-mediated inhibition of $\mathrm{p} 21^{\mathrm{Waf} 1 /}$ Cip1 enhanced the anti-tumor effects of DNA-damaging agents such as doxorubicin, etoposide, and CPT11 in H28 and H2052 cells [54]. Inoue et al. reported that sorafenib downregulated $\mathrm{p} 21^{\text {Waf1/Cip1 }}$ levels and promoted cell death in renal cell carcinoma and hepatocellular carcinoma when used in combination with DNA-damaging agents such as paclitaxel or doxorubicin [55]. Therefore, cSBL + DNAdamaging agents (with the exception of cisplatin) might be an effective therapeutic strategy for mesothelioma. The proposed mechanisms of action of the combination treatments are shown in Figure 7.

In conclusion, cSBL exhibits a potent anti-tumor effect in multiple mesothelioma cell lines due to its cytotoxic activity and high selectivity for cancer cells compared to either pemetrexed or cisplatin. Pemetrexed + cSBL exhibited a strong synergistic effect that was comparable or even superior to the standard regimen of pemetrexed + cisplatin. We propose that the synergistic effect results from the combination of the cytostatic effect of pemetrexed and the cytotoxic effect of cSBL. Therefore, $\mathrm{cSBL}$ has therapeutic potential for mesothelioma.

\section{MATERIALS AND METHODS}

\section{Cell culture}

The H28, H2452, and MSTO mesothelioma cell lines and immortalized, non-malignant MeT-5A mesothelial cell line were purchased from American Type Cell Culture Collection (Manassas, VA, USA). The MESO-1 and MESO-4 mesothelioma cell lines were obtained from Riken Cell Bank (Tsukuba, Japan). H28, H2452, MSTO, MESO-1, and MESO-4 cells were cultured in RPMI-1640 medium supplemented with 10\%

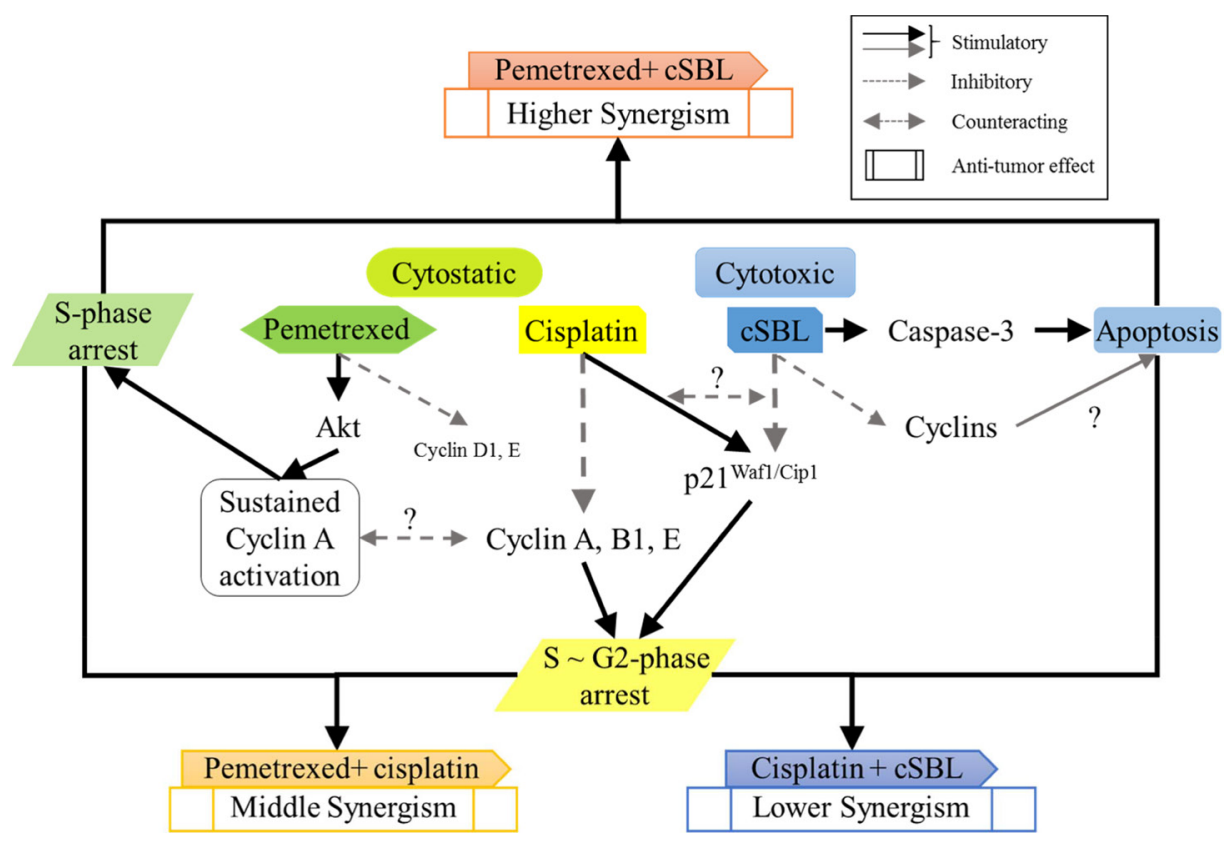

Figure 7: Schematic representation of the molecular mechanisms underlying the synergistic effects of each combination treatment in $\mathrm{H} 28$ cells. 
fetal bovine serum (FBS). MeT-5A cells were cultured in Medium 199 with Earle's balanced salt solution (75 mM L-Gln and $1.25 \mathrm{~g} / \mathrm{L}$ sodium bicarbonate) supplemented with $3.3 \mathrm{nM}$ epidermal growth factor (EGF), $400 \mathrm{nM}$ hydrocortisone, $870 \mathrm{nM}$ insulin, $20 \mathrm{mM}$ HEPES, and 10\% FBS. All cells were cultured with $100 \mathrm{U} / \mathrm{mL}$ penicillin and $100 \mu \mathrm{g} / \mathrm{mL}$ streptomycin at $37^{\circ} \mathrm{C}$ in a $95 \%$ air and $5 \% \mathrm{CO}_{2}$ atmosphere.

\section{Reagents}

cSBL was isolated using sequential chromatography with Sephadex G75, DEAE-cellulose, hydroxyapatite, and SP-Sepharose as previously described [15]. Pemetrexed disodium heptahydrate was purchased from LC Laboratories (Woburn, MA, USA). Cisplatin was purchased from WAKO Pure Chemical Industries, Ltd. (Osaka, Japan). The caspase-3 polyclonal antibody and cyclin B1 (D5C10), cyclin D1 (92G2), p21 $1^{\text {Wafl/Cipl }}$ (12D1), Akt (pan) (11E7), and phospho-Akt (Ser473) rabbit monoclonal antibodies were purchased from Cell Signaling Technology (Beverly, MA, USA). The cyclin A rabbit polyclonal antibody (H-432) and cyclin E mouse monoclonal antibody (HE12) were purchased from Santa Cruz Biotechnology Inc. (CA, USA). The $\beta$-actin antibody from Sigma-Aldrich (Tokyo, Japan) and horseradish peroxidase (HRP)-conjugated anti-mouse IgG were purchased from Zymed (South San Francisco, CA, USA). HRP-conjugated anti-rabbit IgG was purchased from Cedarlane (Hornby, Ontario, Canada), and the Caspase-Glo ${ }^{\mathrm{TM}}$ 3/7 Assay was purchased from Promega (Madison, WI, USA).

\section{Cell viability assays}

Cell viability was determined using the WST-8 assay. Cells $\left(5 \times 10^{4}\right.$ cells $\left./ \mathrm{mL}\right)$ cultured in 96 -well plates (100 $\mu \mathrm{L} /$ well) were treated with various concentration of pemetrexed, cisplatin, or cSBL for $72 \mathrm{~h}$. The cells were incubated with Cell Count Reagent SF (Nacalai Tesque Inc., Kyoto, Japan) at $37^{\circ} \mathrm{C}$ in a $5 \% \mathrm{CO}_{2}$ atmosphere for $1-4 \mathrm{~h}$. The absorbance of the resulting product at $450 \mathrm{~nm}$ was measured and the background absorbance at $650 \mathrm{~nm}$ subtracted. The $\mathrm{IC}_{50}$ was calculated using GraphPad Prism 5.0 (San Diego, CA, USA). Experiments were conducted in triplicate.

\section{Drug combination studies}

The effect of combination treatment on cell viability was assessed using WST-8 assays. The concentration of the individual components was based on $\mathrm{IC}_{50}$ values obtained in the single treatment experiments. CI values were calculated using the CompuSyn software (ComboSyn Inc., Paramus, NJ, USA) as previously described [56]. CI values $<1$ indicated a synergistic effect and CI values $>1$ indicated an antagonistic effect.

\section{Annexin V staining and PI incorporation assays}

To evaluate apoptosis, we evaluated annexin $\mathrm{V}$ binding and PI incorporation using a MEBCYTO apoptosis kit (MBL, Nagoya, Japan) according to the manufacturer's instructions. Cells $\left(5 \times 10^{4}\right.$ cells $\left./ \mathrm{mL}\right)$ cultured in 12 -well plates $(1 \mathrm{~mL} /$ well $)$ were treated with pemetrexed $(20 \mu \mathrm{M})$, cisplatin $(40 \mu \mathrm{M})$, or cSBL $(1 \mu \mathrm{M})$. Fluorescence intensity was detected using a FACScalibur flow cytometer, and the data analyzed using the CELLQuest software (BD Biosciences, Franklin Lakes, NJ, USA).

\section{Detection of caspase-3 activity}

The level of activated caspase- 3 was analyzed using western blot assays with an antibody against cleaved (activated) caspase-3. Cells $\left(5 \times 10^{4}\right.$ cells $\left./ \mathrm{mL}\right)$ cultured in 6 -well plates $(2 \mathrm{~mL} /$ well $)$ were treated with pemetrexed $(20 \mu \mathrm{M})$, cisplatin $(40 \mu \mathrm{M})$, or cSBL $(1 \mu \mathrm{M})$ for $72 \mathrm{~h}$. Whole cell lysates were prepared using extraction buffer (150 mM NaCl, 10 mM Tris-HCl [pH 7.4], 5 mM EDTA, $1 \%$ Nonidet P-40, 0.1\% sodium deoxycholate, and $0.1 \%$ sodium dodecyl sulfate) supplemented with 1 tablet $/ 10 \mathrm{~mL}$ cOmplete, Mini, EDTA-free Protease Inhibitor Cocktail (Roche Applied Science, Indianapolis, IN, USA) and 1 tablet/10 mL PhosSTOP phosphatase inhibitor (Roche Applied Science). Soluble proteins were collected and protein concentration measured using a BCA Protein Assay Kit (Thermo Fisher Scientific, Waltham, MA, USA) according to the manufacturer's instructions. The proteins were separated using SDS-PAGE and transferred to Immobilon-P Transfer Membranes (Merck Millipore, Billerica, MA, USA). Membranes were sequentially incubated with primary and secondary antibodies diluted in Can Get Signal (Toyobo CO., LTD., Osaka, Japan). The protein bands were detected using ECL Prime Western Blotting Detection Reagent (GE Healthcare, Little Chalfont, UK).

Caspase-3 enzymatic activity was measured using a Caspase-Glo ${ }^{\mathrm{TM}}$ Assay. Cells $\left(5 \times 10^{4}\right.$ cells $\left./ \mathrm{mL}\right)$ cultured in white 96 -well plates $(25 \mu \mathrm{L} /$ well $)$ were treated with pemetrexed $(20 \mu \mathrm{M})$, cisplatin $(40 \mu \mathrm{M})$, or cSBL $(1 \mu \mathrm{M})$ for $72 \mathrm{~h}$ in triplicate. Caspase-Glo ${ }^{\mathrm{TM}}$ Reagent $(25 \mu \mathrm{L})$ was added to each well and the contents of the wells mixed using a plate shaker for 30 seconds. The cells were incubated at $37^{\circ} \mathrm{C}$ in a $5 \% \mathrm{CO}_{2}$ atmosphere for $1 \mathrm{~h}$. The luminescence in each well was measured using GloMax ${ }^{\mathrm{TM}}$ Multi Detection System (Promega, Madison, WI, USA).

\section{Cell proliferation assays}

Cell proliferation was quantified using a Muse $^{\mathrm{TM}}$ Count \& Viability Kit (Merck Millipore, Billerica, MA, USA). Cells $\left(5 \times 10^{4}\right.$ cells $\left./ \mathrm{mL}\right)$ cultured in 24-well plates $(500 \mu \mathrm{L} /$ well $)$ were treated with pemetrexed $(20 \mu \mathrm{M})$, cisplatin $(40 \mu \mathrm{M})$, or cSBL $(1 \mu \mathrm{M})$ for $0-72 \mathrm{~h}$. The cells 
were collected at $24 \mathrm{~h}$ intervals and combined with Muse $\mathrm{T}^{\mathrm{TM}}$ Count \& Viability Reagent in which both viable and non-viable cells are differentially stained based on their permeability to the DNA-binding dyes (cells:reagent $=1: 9$ ). The total number of viable or dead cells was counted using a Muse ${ }^{\mathrm{TM}}$ Cell Analyzer (Merck Millipore).

\section{Cell cycle analysis}

Changes in cell cycle progression induced by $72 \mathrm{~h}$ of treatment with pemetrexed $(20 \mu \mathrm{M})$, cisplatin $(40 \mu \mathrm{M})$, or cSBL $(1 \mu \mathrm{M})$ were evaluated using a CycleTEST $^{\mathrm{TM}}$ Plus DNA Reagent Kit (BD Biosciences) according to the manufacturer's instructions. Cells $\left(5 \times 10^{4}\right.$ cells $\left./ \mathrm{mL}\right)$ were cultured in 12-well plates $(1 \mathrm{~mL} /$ well $)$. Fluorescence intensity was detected using a FACScalibur flow cytometer and the data analyzed using the CELLQuest software (BD Biosciences). Cell cycle progression was analyzed using Flowing Software 2 (Perttu Terho, Turku Centre for Biotechnology, Finland). The levels of cell cycle

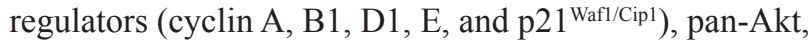
and phospho-Akt were evaluated by western blot analysis.

\section{Statistical analysis}

The results from at least three independent experiments performed in triplicate are expressed as the mean \pm standard deviation (SD). Statistical analyses were conducted using GraphPad Prism 5.0 and comparisons made using one-way analysis of variance (ANOVA) followed by Bonferroni post-hoc tests.

\section{CONFLICTS OF INTEREST}

The authors declare that there are no conflicts of interest.

\section{FUNDING}

This study was supported by the 'Strategic Research' Project (2012-2017) for Private Universities from the Ministry of Education, Culture, Sports, Science and Technology of Japan and a Grant-in-Aid for Young Scientists (B) (No. 26870527 to Takeo Tatsuta).

\section{REFERENCES}

1. Tsao AS, Wistuba I, Roth JA, Kindler HL. Malignant pleural mesothelioma. J Clin Oncol. 2009; 27:2081-90.

2. Robinson BW, Lake RA. Advances in malignant mesothelioma. N Engl J Med. 2005; 353:1591-603.

3. Owen WG. Diffuse Mesothelioma and Exposure to Asbestos Dust in the Merseyside Area. Br Med J. 1964; 2:214-8.

4. Matsuzaki H, Lee S, Maeda M, Kumagai-Takei N, Nishimura Y, Otsuki T. FoxO1 regulates apoptosis induced by asbestos in the MT-2 human T-cell line. J Immunotoxicol. 2016; 13:620-7.

5. Mensi C, De Matteis S, Dallari B, Riboldi L, Bertazzi PA, Consonni D. Incidence of mesothelioma in Lombardy, Italy: exposure to asbestos, time patterns and future projections. Occup Environ Med. 2016; 73:607-13.

6. Albin M, Magnani C, Krstev S, Rapiti E, Shefer I. Asbestos and cancer: An overview of current trends in Europe. Environ Health Perspect. 1999 (Suppl 2); 107:289-98.

7. Lanphear BP, Buncher CR. Latent period for malignant mesothelioma of occupational origin. J Occup Med. 1992; 34:718-21.

8. Selikoff IJ, Hammond EC, Seidman H. Latency of asbestos disease among insulation workers in the United States and Canada. Cancer. 1980; 46:2736-40.

9. Niklinski J, Niklinska W, Chyczewska E, Laudanski J, Naumnik W, Chyczewski L, Pluygers E. The epidemiology of asbestos-related diseases. Lung Cancer. 2004; 45:S7-15.

10. Vogelzang NJ, Rusthoven JJ, Symanowski J, Denham C, Kaukel E, Ruffie P, Gatzemeier U, Boyer M, Emri S, Manegold C, Niyikiza C, Paoletti P. Phase III study of pemetrexed in combination with cisplatin versus cisplatin alone in patients with malignant pleural mesothelioma. J Clin Oncol. 2003; 21:2636-44.

11. Krug LM. An overview of chemotherapy for mesothelioma. Hematol Oncol Clin North Am. 2005; 19:1117-36.

12. Leon L, Gemelli M, Sciarrillo R, Avan A, Funel N, Giovannetti E. Synergistic Activity of the c-Met and Tubulin Inhibitor Tivantinib (ARQ197) with Pemetrexed in Mesothelioma Cells. Curr Drug Targets. 2014; 15:1331-40.

13. Hazarika M, White RM, Booth BP, Wang YC, Ham DYL, Liang CY, Rahman A, Gobburu JVS, Li N, Sridhara R, Morse DE, Lostritto R, Garvey P, et al. Pemetrexed in malignant pleural mesothelioma. Clin Cancer Res. 2005; 11:982-92.

14. Kitazono-Saitoh M, Takiguchi Y, Kitazono S, Ashinuma H, Kitamura A, Tada Y, Kurosu K, Sakaida E, Sekine I, Tanabe N, Tagawa M, Tatsumi K. Interaction and crossresistance of cisplatin and pemetrexed in malignant pleural mesothelioma cell lines. Oncol Rep. 2012; 28:33-40.

15. Nitta K, Takayanagi G, Kawauchi H, Hakomori S. Isolation and characterization of Rana catesbeiana lectin and demonstration of the lectin-binding glycoprotein of rodent and human tumor cell membranes. Cancer Res. 1987; 47:4877-83.

16. Nitta K, Ozaki K, Ishikawa M, Furusawa S, Hosono M, Kawauchi H, Sasaki K, Takayanagi Y, Tsuiki S, Hakomori S. Inhibition of cell proliferation by Rana catesbeiana and Rana japonica lectins belonging to the ribonuclease superfamily. Cancer Res. 1994; 54:920-7.

17. Nitta K, Oyama F, Oyama R, Sekiguchi K, Kawauchi H, Takayanagi Y, Hakomori S, Titani K. Ribonuclease activity of sialic acid-binding lectin from Rana catesbeiana eggs. Glycobiology. 1993; 3:37-45. 
18. Tatsuta T, Hosono M, Miura Y, Sugawara S, Kariya Y, Hakomori S, Nitta K. Involvement of ER stress in apoptosis induced by sialic acid-binding lectin (leczyme) from bullfrog eggs. Int J Oncol. 2013; 43:1799-808.

19. Tatsuta T, Hosono M, Sugawara S, Kariya Y, Ogawa Y, Hakomori S, Nitta K. Sialic acid-binding lectin (leczyme) induces caspase-dependent apoptosis-mediated mitochondrial perturbation in Jurkat cells. Int J Oncol. 2013; 43:1402-12.

20. Ogawa Y, Sugawara S, Tatsuta T, Hosono M, Nitta K, Fujii Y, Kobayashi H, Fujimura T, Taka H, Koide Y, Hasan I, Matsumoto R, Yasumitsu H, et al. Sialylglycoconjugates in cholesterol-rich microdomains of P388 cells are the triggers for apoptosis induced by Rana catesbeiana oocyte ribonuclease. Glycoconj J. 2014; 31:171-84.

21. Tang $\mathrm{CH}, \mathrm{Hu} \mathrm{CC}$, Wei CW, Wang JJ. Synergism of Rana catesbeiana ribonuclease and IFN-gamma triggers distinct death machineries in different human cancer cells. FEBS Lett. 2005; 579:265-70.

22. Tseng HH, Yu YL, Chen YL, Chen JH, Chou CL, Kuo TY, Wang JJ, Lee MC, Huang TH, Chen MH, Yiang GT. RCRNase-induced cell death in estrogen receptor positive breast tumors through down-regulation of $\mathrm{Bcl}-2$ and estrogen receptor. Oncol Rep. 2011; 25:849-53.

23. $\mathrm{Hu} \mathrm{CC}$, Tang CH, Wang JJ. Caspase activation in response to cytotoxic Rana catesbeiana ribonuclease in MCF-7 cells. FEBS Lett. 2001; 503:65-8.

24. Kariya Y, Tatsuta T, Sugawara S, Kariya Y, Nitta K, Hosono M. RNase activity of sialic acid-binding lectin from bullfrog eggs drives antitumor effect via the activation of p38 MAPK to caspase-3/7 signaling pathway in human breast cancer cells. Int J Oncol. 2016; 49:1334-42.

25. Tatsuta T, Hosono M, Takahashi K, Omoto T, Kariya Y, Sugawara S, Hakomori S, Nitta K. Sialic acid-binding lectin (leczyme) induces apoptosis to malignant mesothelioma and exerts synergistic antitumor effects with TRAIL. Int J Oncol. 2014; 44:377-84.

26. Liao YD, Huang HC, Chan HJ, Kuo SJ. Large-scale preparation of a ribonuclease from Rana catesbeiana (bullfrog) oocytes and characterization of its specific cytotoxic activity against tumor cells. Protein Expr Purif. 1996; 7:194-202.

27. Hu CC, Lee YH, Tang CH, Cheng JT, Wang JJ. Synergistic cytotoxicity of Rana catesbeiana ribonuclease and IFNgamma on hepatoma cells. Biochem Biophys Res Commun. 2001; 280:1229-36.

28. Lee YH, Wei CW, Wang JJ, Chiou CT. Rana catesbeiana ribonuclease inhibits Japanese encephalitis virus (JEV) replication and enhances apoptosis of JEV-infected BHK21 cells. Antiviral Res. 2011; 89:193-8.

29. Vert A, Castro J, Ribó M, Benito A, Vilanova M. A nucleardirected human pancreatic ribonuclease (PE5) targets the metabolic phenotype of cancer cells. Oncotarget. 2016; 7:18309-24. doi: 10.18632/oncotarget.7579.
30. Qu K, Lin T, Wei J, Meng F, Wang Z, Huang Z, Wan Y, Song S, Liu S, Chang H, Dong Y, Liu C. Cisplatin induces cell cycle arrest and senescence via upregulating P53 and P21 expression in HepG2 cells. Nan Fang Yi Ke Da Xue Xue Bao. 2013; 33:1253-9.

31. Chen KC, Yang TY, Wu CC, Cheng CC, Hsu SL, Hung HW, Chen JW, Chang GC. Pemetrexed induces S-phase arrest and apoptosis via a deregulated activation of Akt signaling pathway. PLoS One. 2014; 9:e97888.

32. Wu DM, Zhang P, Xu GC, Tong AP, Zhou C, Lang JY, Wang CT. Pemetrexed induces G1 phase arrest and apoptosis through inhibiting Akt activation in human non small lung cancer cell line A549. Asian Pac J Cancer Prev. 2015; 16:1507-13.

33. Buqué A, Muhialdin JS, Muñoz A, Calvo B, Carrera S, Aresti U, Sancho A, Rubio I, López-Vivanco G. Molecular mechanism implicated in Pemetrexed-induced apoptosis in human melanoma cells. Mol Cancer. 2012; 11:25.

34. Jia Y, Sun H, Wu H, Zhang H, Zhang X, Xiao D, Ma X, Wang Y. Nicotine Inhibits Cisplatin-Induced Apoptosis via Regulating alpha5-nAChR/AKT Signaling in Human Gastric Cancer Cells. PLoS One. 2016; 11:e0149120.

35. Vandermeers F, Hubert P, Delvenne P, Mascaux C, Grigoriu B, Burny A, Scherpereel A, Willems L. Valproate, in combination with pemetrexed and cisplatin, provides additional efficacy to the treatment of malignant mesothelioma. Clin Cancer Res. 2009; 15:2818-28.

36. Indovina P, Marcelli E, Di Marzo D, Casini N, Forte IM, Giorgi F, Alfano L, Pentimalli F, Giordano A. Abrogating $\mathrm{G}_{2} / \mathrm{M}$ checkpoint through WEE1 inhibition in combination with chemotherapy as a promising therapeutic approach for mesothelioma. Cancer Biol Ther. 2014; 15:380-8.

37. Kataoka Y, Yamamoto Y, Otsuki T, Shinomiya M, Terada T, Fukuma S, Yamazaki S, Hirabayashi M, Nakano T, Fukuhara S. A new prognostic index for overall survival in malignant pleural mesothelioma: the rPHS (regimen, PS, histology or stage) index. Jpn J Clin Oncol. 2015; 45:562-8.

38. Ortolan E, Giacomino A, Martinetto F, Morone S, Lo Buono N, Ferrero E, Scagliotti G, Novello S, Orecchia S, Ruffini E, Rapa I, Righi L, Volante M, Funaro A. CD157 enhances malignant pleural mesothelioma aggressiveness and predicts poor clinical outcome. Oncotarget. 2014; 5:6191-205. doi: 10.18632/oncotarget.2186.

39. Tatsuta T, Sugawara S, Takahashi K, Ogawa Y, Hosono M, Nitta K. Leczyme: A New Candidate Drug for Cancer Therapy. Biomed Res Int. Hindawi Publishing Corporation. 2014; 2014:1-10.

40. Tatsuta T, Sugawara S, Takahashi K, Ogawa Y, Hosono M, Nitta K. Cancer-selective induction of apoptosis by leczyme. Front Oncol. 2014; 4:139.

41. Nitta K, Ozaki K, Tsukamoto Y, Furusawa S, Ohkubo Y, Takimoto H, Murata R, Hosono M, Hikichi N, Sasaki K. Characterization of a Rana catesbeiana lectin-resistant mutant of leukemia P388 cells. Cancer Res. 1994; 54:928-34. 
42. Chang BD, Broude EV, Dokmanovic M, Zhu H, Ruth A, Xuan Y, Kandel ES, Lausch E, Christov K, Roninson IB. A senescence-like phenotype distinguishes tumor cells that undergo terminal proliferation arrest after exposure to anticancer agents. Cancer Res. 1999; 59:3761-7.

43. Ding $\mathrm{H}$, Han $\mathrm{C}$, Guo $\mathrm{D}$, Wang $\mathrm{D}$, Chen CS, D'Ambrosio SM. OSU03012 activates Erk1/2 and Cdks leading to the accumulation of cells in the S-phase and apoptosis. Int J Cancer. 2008; 123:2923-30.

44. Adachi S, Ito H, Tamamori-Adachi M, Ono Y, Nozato T, Abe S, Ikeda Ma, Marumo F, Hiroe M. Cyclin A/cdk2 activation is involved in hypoxia-induced apoptosis in cardiomyocytes. Circ Res. 2001; 88:408-14.

45. Zhan Z, He K, Zhu D, Jiang D, Huang YH, Li Y, Sun C, Jin YH. Phosphorylation of Rad9 at Serine 328 by Cyclin A-Cdk2 Triggers Apoptosis via Interfering Bcl-xL. PLoS One. 2012; 7:e44923.

46. Pestell RG, Albanese C, Reutens AT, Segall JE, Lee RJ, Arnold A. The cyclins and cyclin-dependent kinase inhibitors in hormonal regulation of proliferation and differentiation. Endocr Rev. 1999; 20:501-34.

47. Cheng M, Olivier P, Diehl JA, Fero M, Roussel MF, Roberts JM, Sherr CJ. The p21(Cip1) and p27(Kip1) CDK "inhibitors" are essential activators of cyclin D-dependent kinases in murine fibroblasts. EMBO J. 1999; 18:1571-83.

48. Flores-Rozas H, Kelmant Z, Dean FB, Pan ZQ, Harper JW, Elledget SJ, O'Donnell M, Hurwitz J. Cdk-interacting protein 1 directly binds with proliferating cell nuclear antigen and inhibits DNA replication catalyzed by the DNA polymerase 6 holoenzyme (cell cycle regulation/ processivity/protein-protein interaction). Biochemistry. 1994; 91:8655-9.
49. Niculescu AB, Chen X, Smeets M, Hengst L, Prives C, Reed SI. Effects of p21(Cip1/Waf1) at both the G1/S and the $G 2 / M$ cell cycle transitions: $p R b$ is a critical determinant in blocking DNA replication and in preventing endoreduplication. Mol Cell Biol. 1998; 18:629-43.

50. Ogryzko VV, Wong P, Howard BH. WAF1 retards S-phase progression primarily by inhibition of cyclin-dependent kinases. Mol Cell Biol. 1997; 17:4877-82.

51. Radhakrishnan SK, Feliciano CS, Najmabadi F, Haegebarth A, Kandel ES, Tyner AL, Gartel AL. Constitutive expression of E2F-1 leads to p21-dependent cell cycle arrest in S phase of the cell cycle. Oncogene. 2004; 23:4173-6.

52. Ramirez JM, Ocio EM, San Miguel JF, Pandiella A. Pemetrexed acts as an antimyeloma agent by provoking cell cycle blockade and apoptosis. Leukemia. 2007; 21:797-804.

53. Baldi A, Piccolo MT, Boccellino MR, Donizetti A, Cardillo I, La Porta R, Quagliuolo L, Spugnini EP, Cordero F, Citro G, Menegozzo M, Calogero RA, Crispi S. Apoptosis induced by piroxicam plus cisplatin combined treatment is triggered by $\mathrm{p} 21$ in mesothelioma. PLoS One. 2011; 6:e23569.

54. Lazzarini R, Moretti S, Orecchia S, Betta PG, Procopio A, Catalano A. Enhanced antitumor therapy by inhibition of p21waf1 in human malignant mesothelioma. Clin Cancer Res. 2008; 14:5099-107.

55. Inoue $\mathrm{H}$, Hwang $\mathrm{SH}$, Wecksler AT, Hammock BD, Weiss RH. Sorafenib attenuates p21 in kidney cancer cells and augments cell death in combination with DNA-damaging chemotherapy. Cancer Biol Ther. 2011; 12:827-36.

56. Chou TC. Drug combination studies and their synergy quantification using the Chou-Talalay method. Cancer Res. 2010; 70:440-6. 